\title{
Una pieza excepcional del Museo Nazionale de Roma y el problema de las lucernas tipo Andújar
}

\author{
dario Bernal Casasola
}

Con motivo de la reciente revisión de los fondos lucernarios del Museo Nazionale Romano con vistas a su clasificación preliminar hemos podido documentar en ellos una pieza de indudable factura hispana ${ }^{1}$. Se trata de una lucerna cuyas características tanto formales (aletas laterales, rostrum yunquiforme) como decorativas (disco decorado con una vénera undecapétala) nos permiten su identificación con el tipo conocido como derivado de la Dressel 3 (López Rodríguez 1982, 381; Amaré Tafalla 19891990, 144).

No conocemos su contexto preciso y como es de suponer al tratarse de un depósito museístico antiguo carece de cualquier referencia estratigráfica que permita precisar su cronología de llegada a la península itálica. No obstante, los datos que hemos podido recabar en la Soprintendenza Archeologica di Roma nos permite asegurar su procedencia del Tíber, constituyendo probablemente parte de las existencias del antiguo Museo Kircheriano ${ }^{2}$.

Agradecemos a C. Pavolini las gestiones realizadas para permitirme la consulta de los fondos del Antiquarium del MNR durante junio de 1992. La colección lychnológica conservada en el mismo, que asciende a más de 10.000 ejemplares, constituye una de las mayores no sólo europeas, sino a nivel mundial, agrupando producciones de cronologia y origen variados. Aún permanece prácticamente inédita, salvo referencias puntuales y la parcela destinada a las lámparas africanas en TSC, ya en prensa. El resto y debido a problemas de financiación, continuará publicándose en pequeñas series. Asimismo reiteramos nuestra gratitud a la Dra. M. Barbera por su entera disposición y amabilidad prestada durante nuestro período de consulta. A la Dra. P. Fraiegari por su ayuda en las consultas en los archivos y ficheros de la citada institución.

La referencia inventarial es la n." 200575 del Catálogo General, formando parte al parecer de un conjunto de 25 piezas de características similares, también con decoración de vénera en el discus. Nuestra pieza, cuyas dimensiones son $10,6 \times 7,5 \times 3$, presenta el rostrum mal restaurado. 
Se trata de un hallazgo singular, pues nos permite la identificación de esta forma fuera de los límites nacionales, cuando su dispersión hasta la fecha no sobrepasaba un ámbito de carácter regional, circunscribiéndose fundamentalmente a la Alta Andalucía, con algunos ejemplares en yacimientos del Norte peninsular (López Rodríguez 1982, 390).

Debemos considerar esta pieza como llegada a las comarcas laciales, via fluvialis, asociada al comercio del preciado aceite bético (con sus inseparables ánforas Dr. 20). Vinculada, pues, al personal de la nave de transporte constituiria bien una pieza de uso de la misma, bien parte de su carga, dada la fácil adquisición en función de la cercanía de los alfares productores a los puertos de embarque del Guadalquivir.

A pesar de carecer por el momento de datos que nos permitan aventurar un exportación masiva y conscientes de que de haber existido ésta hubiera dejado alguna huella palpable en el Mediterráneo, conviene no olvidar la posibilidad de que pudiera tratarse de un tipo de mercancía secundaria que acompañara a las ánforas olearias en el viaje para su distribución ulterior en Italia y el resto del imperio. Este fenómeno de utilizar las cerámicas para rellenar los huecos dejados por la mercancía principal del cargamento ha sido bien documentado en el caso de otras categorías cerámicas, tanto en época republicana como bajoimperial, caso de los barnices negros y las vajillas finas de mesa africanas, respectivamente (MOREL 1990, 403-407; AtLANTE I, 1981, 11-18; Roca 1991b, 233).

Por el momento, y tal como ha quedado propuesto en el caso de la distribución mediterránea de carácter puntual de la TSH (ATLANTE II , 1985, 111), no debemos aventurar conclusiones hasta que un mayor volumen de hallazgos nos lo permita. Por ahora consideramos nuestra pieza como un dato aislado.

Respecto a la localización de los talleres emisores de este tipo de producciones, hasta el momento conocíamos el ya citado complejo de Los Villares de Andújar (Jaén), sobre todo a través de sus producción de sigillatas (recientemente, RocA, 1991, con toda la bibliografía actualizada). La producción de lucernas allí documentada (SоTOMAYOR 1981, 307-313) se caracteriza por presentar pastas amarillentas-blancas muy típicas, así como cuatro marcas/firmas específicas: M. C. S. (retro), T, tres círculos concéntricos rehundidos y una hoja acorazonada (fig. 1, A). En lo referente a nuestra pieza, dada la coincidencia de aparecer sellada por una hoja acorazonada, unido a los caracteres macroscópicos de la pasta, nos inclinábamos a englobarla entre las producciones de dicho centro ${ }^{3}$.

Una pasta porosa, arenosa, con pequeñas vacuolas, muy depurada y con desgrasantes 


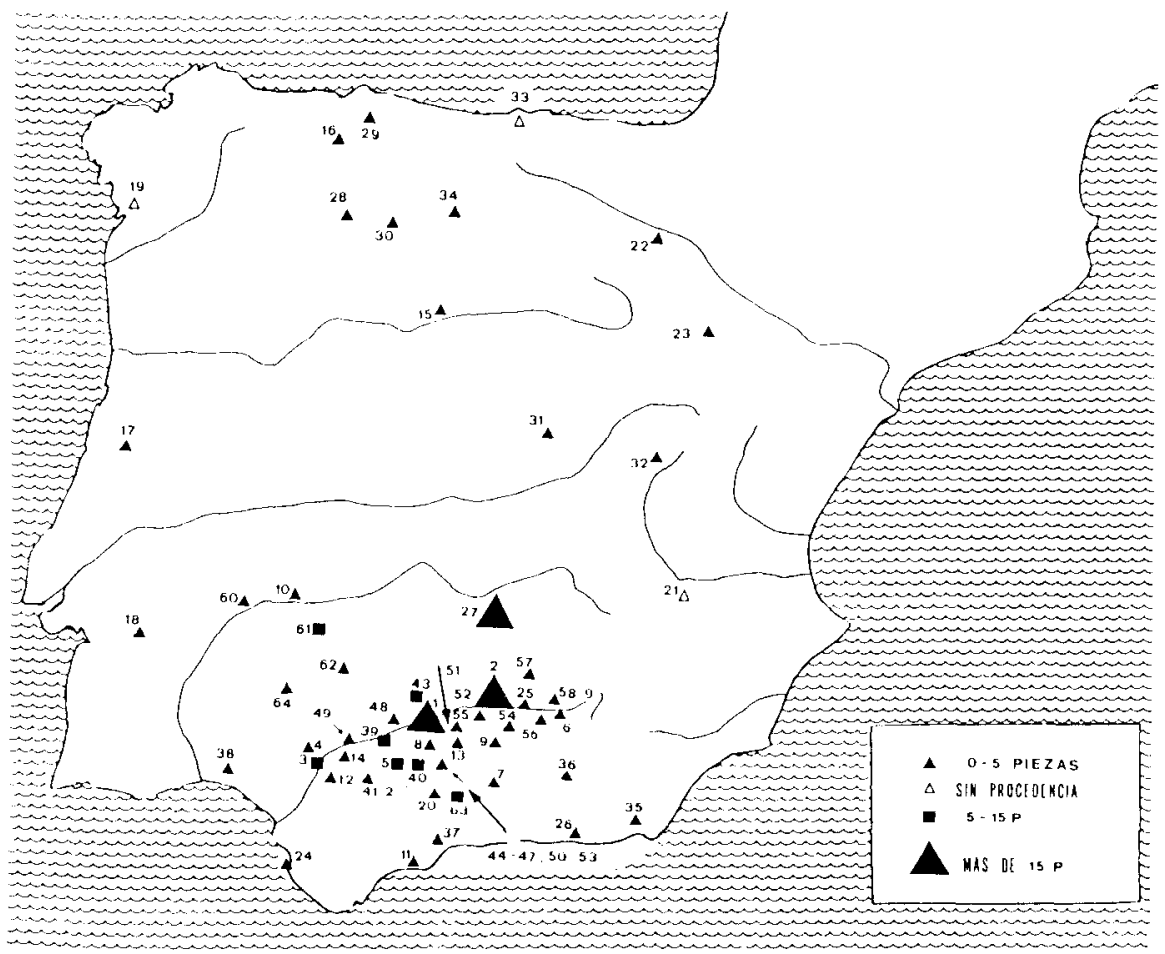

Fig. 3. Mapa de distribución de las lucernas tipo Andujar en la peninsula iberica.
1) Córdoba
22) Calahorra
2) Andújar
23) Bibilis
44) Montilla
3) M. Arqueológico
24) Cádiz
25) Cástulo
4) Itálica
26) Cerro Montecristo
45) Fuente Tójar
Sevilla
27) La Bienvenida
28) Astorga
29) Mieiras de Beloño
46) Nueva Carteia
5) Osuna
6) Peal
7) Brancana
8) Monturque
30) Cuevas Barrera Blanca
31) Complutum
32) Segóbriga
33) Museo Santander
10) Mérida
11) Marbella
12) Alcalá de Guadaira
34) Herrera de Pisuerga
13) Baena
35) Campo de S. Juan
47) Cabra
48) Peñaflor
14) Carmona
36) Guadix
37) Málaga
38) Riotinto
16) Puelles
39) Écija
40) Estepa
49) Palma del Río
50) Espejo
51) Cañete de Torres
52) Pedro Abad
53) Porcuna
54) Jaén
55) Porcuna
56) Úbeda
57) La Carolina
58) S. Tomé
59) Sta. Elena
60) Badajoz
61) Zalamea
18) Museo Évora
41) Marchena
19) Museo Pontevedra
42) Cañada Honda
62) Azuaga
63) Los Castillones
20) El Castillón
43) Cerro Muriano
64) Fuente del León
21) Museo Albacete 
Por otro lado, y como anotación al funcionamiento interno del conjunto de Los Villares, señalamos la discordancia existente entre las firmas de la TSH de producción local y las de las lucernas ${ }^{4}$. Como hipótesis de trabajo y dada la no concidencia entre unas y otras, en ningún caso, podríamos pensar en la existencia de grupos alfareros bien diferenciados en sus respectivas labores productivas, muy especializados y destinados a trabajar por separado las dos clases cerámicas. Un análisis más profundo permitirá su identificación.

Dado el ámbito altoimperial en el que nos movemos en la Isturgi romana, la cronología de las lucernas de sus talleres se centra en época Julio-Claudia, con pervivencias hasta época Flavia. Otros contextos andaluces parecen corroborar estas dataciones (LOPEZ RODRiguez 1982, 381 382).

El hecho de haber sido Andújar el primer centro alfarero en el que quedó claramente documentada la producción de lucernas de estas características ha originado que en la literatura arqueológica de los años siguientes esta forma quedase bautizada terminológicamente con el apelativo de lucernas "de Andújar", o en su defecto "derivadas de la Dr. 3" (término este último acuñado por López Rodríguez 1982, 381). Las características tipológicas de esta forma nos inducen a englobarla con total propiedad en el tercer tipo de la clasificación de Dressel, si bien podemos considerarla como derivada del mismo en virtud de su cronología algo más tardía respecto al prototipo. Respecto a la primera de las acepciones empleadas, nosotros conservamos tal denominación por tradición, pero en un sentido más amplio: denominaremos, por tanto, a las piezas de esta índole lucernas tipo Andújar, y no lucernas de Andújar.

La razón de ello es la confluencia de una serie de indicios que nos permiten aventurar con bastante fiabilidad la manufactura de lámparas de estas características en otros talleres peninsulares. Los datos que hemos podido reunir hasta el momento nos inducen a considerar a Córdoba como emisora de lucernas tipo Andújar. La ubicación espacial precisa del taller/talleres en el subsuelo cordobés se nos escapa por el momento, pero pensamos que queda dentro de los límites del casco urbano actual.

no visibles. Color amarillento/pajizo ( $K$ 75/77) de la tabla Callegux, A. Notice sur le Code des Couleurs des sols, Ed. Boubée. La identificamos con el grupo D1 de Sotomayor (1981, pág. 364)

Entre las primeras tenemos M.S.M., Cudas, Quartio, Titi Opi... (RocA 1991a, pág. 394), frente a M.C.S (retro) T, hoja acorazonada bilobulada y tres circulos concéntricos rehundidos de las lucernas (SOTOMAYOR 1981, figs. 3 y 4 ). 
El primer dato que aportamos es el reciente hallazgo de piezas de nuestras características en Córdoba, en una excavación de urgencia en la zona de la estación ferroviaria. Aparecieron asociadas al vertedero de un alfar destinado a la fabricación de cerámicas comunes de formas muy variadas, tanto abiertas (cuencos) como cerradas (botellas, jarras, cantimploras). También producia formas de paredes finas (vasitos de la forma Mayet 37). Estos materiales unidos a la documentación en el mismo vertedero de cerámicas de barniz rojo julio-claudio, tipo Peñaflor, ha permitido a sus excavadores centrar su cronología en el siglo I d.C. (MARFILVENTURA 1991, 26-41). La falta de un estudio preciso del conjunto no nos permite aún considerar estas lucernas como productos de dicho complejo, pero su hallazgo resulta muy sintomático.

En segundo lugar contamos con la documentación visual por nosotros mismos de lámparas tipo Andújar, fruto de expoliaciones en un área impresa de Córdoba (Bernal Casasola 1991-2). Se trata de desechos de alfar - piezas deformadas y adheridas unas a otras-procedentes, sin duda alguna, del vertedero de una alfarería de la Colon ia Patricia. Un dato adicional de gran interés lo constituye el hecho de que estas lucernas se encontraban en un lote asociadas a otros defectos de fabricación correspondientes a un tipo poco conocido cuya clasificación es ciertamente problemática, dada la poca cantidad de hallazgos conocida. Recientemente también ha sido aventurada la fabricación peninsular de esta última forma -que aquí queda totalmente confirmada-, relacionándolas con la producción jiennense, en virtud de la afinidad entre las marcas de Andújar y las existentes en algunas piezas de esta tipología (AMARÉ 1989-1990, $146, n .^{\circ} 4$ ). La morfología de estas piezas (rostrum yunquiforme, ausencia de discus y orla decorada a base de bandas radiales aplicadas con círculos impresos) es muy caracterizadora. Respecto a la cronología, materiales recientemente recuperados en la calle Ángel Saavedra, n. ${ }^{10}$, de Córdoba, arrojan una cronología republicana, dada su aparición asociada a barnices negros (campanienses A y de producción indeterminada) y cerámicas pintadas fechadas en el tránsito del siglo $\|$ al siglo I a.C. (VENTURA 1991, 260-270). Posteriores hallazgos contextualizados ayudarán a precisarla, pues los materiales hasta hoy conocidos no permiten extraer conclusiones de carácter cronológico ${ }^{5}$. Contamos, no obstante, con una

El único dato discordante lo constituye el hecho de que la cronología de estas piezas es bastante anterior a la de las lucernas tipo Andujar. En el caso de corroborarse esta datación asi como el carácter sincrónico de ambas formas, tendriamos que pensar en retrasar las fechas del taller de Cordoba, y con él la cronología inicial de este tipo de piezas en la Península. 
serie de hallazgos de estas caracteristicas distribuidos por el territorio andaluz, aunque su número no supera la decena ${ }^{6}$.

Otro elemento que nos ha inducido a considerar esta producción local en Córdoba ha sido tanto la distribución general de las lucernas tipo Andújar en la Bética como su particular concentración en Córdoba ${ }^{7}$.

En cuanto a la Bética, los datos cuantitativos presentados por Moreno (1991, 1754-1763) nos permiten observar claramente una preponderancia del tipo en Córdoba. En todo el territorio provincial se conocen unas 260 piezas publicadas, correspondientes a las cuatro variantes del tipo Andújar ya definidas por Sotomayor $(1981,364)$. De ellas, algo más del 40 por 100 se ubica en Córdoba y en su entorno más inmediato. Este dato ya nos da que pensar y resulta más que ilustrativo, pues desde un punto de vista numérico aventaja notablemente a Jaén, provincia colindante en la que se encuentra Andújar, duplicando en número de ejemplares allí documentado.

Además, la distribución local permite precisar aún más este panorama. De esas 111 piezas, ya mencionadas, 80 proceden de la misma capital de la provincia (un 75 por 100 aproximadamente).

Si consideramos por un momento el diagrama de barras (fig. 2), que ilustra los diversos tipos de lucernas romanas hallados en Córdoba y sus concentraciones respectivas, notamos una desproporción muy acusada entre algunos de ellos.

El tipo que sobresale entre todos los demás es el representado por el $n .^{\circ} 44^{8}$, que supera al resto con gran diferencia. Si observamos la presencia de los demás tipos, aún en un intervalo cronológico más amplio, nos damos cuenta que el único grupo que se le aproxima en número es el representado por los tipos Moreno 50-57, que sumados ofrecen también una concentración elevada. Estos tipos corresponden a una producción

- Son las piezas $n{ }^{\circ} 89,689,2.956,2.282,2.273,1.961$ y 1.064 , de Almería, Córdoba, Sevilla, Badajoz, Úbeda y Córdoba respectivamente (MORENO 1991, pág. 560, lám. CCLXXII-III).

Somos conscientes de que parte de las conclusiones extraíbles a nivel estadístico son exponente de un hecho tan simple como la mayor o menor cantidad de estudios en una zona determinada y del vacio de estudios científicos en otras (PAVOLINI 1983, pág. 43). En nuestro caso, al haber sido analizada la Bética con un carácter global (MORENO 1990. passim) nos permite reducir considerablemente las posibilidades de error en la interpretación cartográfica en este ámbito geográfico

"El tipo 44 de Moreno se corresponde con el tipo D1 de Sotomayor. En realidad y para un análisis general del tipo consideramos en conjunto los $n .40-44$ de Moreno. pues cada uno de ellos se corresponde con otro de Sotomayor: Moreno $40=$ Sotomayor A1; $41=A 2 ; 42 \approx B$ : $43 \div$ C. 


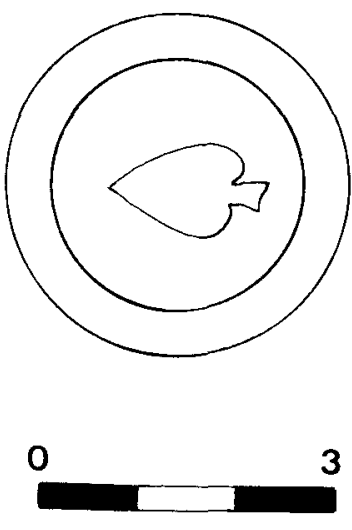

$\mathbf{A}$

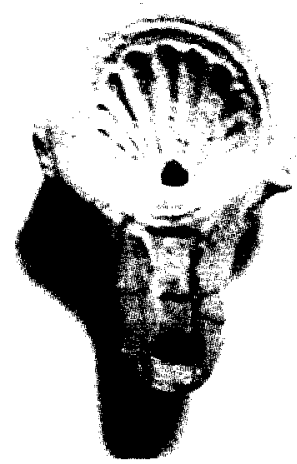

$\mathbf{B}$

Fig. 1. Marca en relieve (A) y nuestra pieza ya resaltada (B).

local de época algo precedente (siglo । a.C.) ya conocida y bien documentada (MORENO, en prensa).

El resto de las concentraciones, ciertamente de carácter minoritario, remarca la presencia de lucernas tipo Andújar en Córdoba y ratifica de manera gráfica la hipótesis de su fabricación local aquí propuesta ${ }^{9}$.

Nos permitimos una puntualización de carácter morfológico: de los cuatro subtipos de Andújar, a los que hemos hecho referencia, el procentaje de aparición de uno de ellos (el subdtipo D de Sotomayor) es sorprendentemente alto respecto a los demás.

De esa cifra total en la Bética de 260 lámparas, ya aludida, 170 de las mismas (un 65 por 100 aproximadamente) pertenecen al subtipo D. Estos datos nos permiten intuir que es ésta la variante más comercializada a todos los niveles, pues incluso los ejemplares documentados al Norte de Sierra Morena se ajustan a esta tipología.

Otro elemento a tener en cuenta son los datos extraíbles de la presencia, concentración y área de distribución de las marcas vinculadas a estas formas.

9 El tipo 11 también destaca respecto a las demás producciones, pero es un hecho normal al tratarse de las producciones de volutas, que es la más frecuente y difundida por todo el mediterráneo durante el siglo I d.C. 
En principio mencionar la limitación en la atribución de una forma a un centro exclusivamente por la firma/marca, pues conocemos la existencia de sucursales de un taller en zonas geográficas diversas que presentan las mismas firmas/marcas que el taller principal, hecho bien documentado en el caso de la TSH (RocA 1991a, 397).

Tenemos documentada la existencia de una marca vinculada a este tipo de lucernas que no se ha documentado en el taller de Andújar. Se trata de un motivo delfiniforme que aparece en hueco sobre la base de algunas piezas. En la Bética conocemos un conjunto de seis derivadas de la Dr. 3 con esta marca, y curiosamente, cinco cordobesas y una granadina (MORENO 1991, 289). Es interesante constatar su documentación en la Tarraconense, sobre una pieza del subtipo D de Sotomayor de Calagurris (AMARÉ 1987, 58).

La distribución espacial de una de las marcas de Andújar, la hoja acorazonada bilobulada, nos refleja una presencia amplisima, desde La Bienvenida en Ciudad Real (FERNÁNDEZ OCHOA 1987, 278) hasta Almería, presentes en toda la Bética salvo en Huelva y Cádiz (MORENo 1991, 304306) siempre asociada al subtipo D de Sotomayor y de nuevo con una clara hegemonia en Córdoba, en una proporción de 7 a 1 respecto a Andújar. También la tenemos fuera de la provincia (SERRANo 1983, 151).

Debemos señalar que esta hoja acorazonada bilobulada no es una marca exclusiva de este tipo de piezas, pues la vamos a encontrar en contextos bastante más tardíos en producciones precisamente cordobesas de manufactura local cuya producción ha sido recientemente identifica$\mathrm{da}{ }^{10}$.

Asimismo, tenemos constancia de otra pieza cordobesa de estas características procedente del Camino Viejo de Almodovar (RoDRIGUEZ NEILA $\left.1978-9,8,9, n .^{\circ} 1\right)$, firmada por el ceramista STRO[BILUS]. De nuevo se trata de otra arca no documentada en Andújar, constituyendo por tanto otro elemento más a favor de la existencia de talleres cordobeses. Se trata, sin lugar a dudas, de un intento de prestigiar los talleres locales mediante la copia de la firma de un alfarero noritálico (posiblemente de Módena) bien conocido, evidenciando una vez más la frecuente costumbre de otorgar mayor calidad a los productos emitidos por una officina plagiando las marcas de otros talleres afamados en el mercado. No es de

\footnotetext{
10 Nosotros hemos documentado la manufactura de tipos cordiformes (Dr. 28) y de otras piezas de tipologías más tardías aún no muy bien perfiladas en una revisión del material de una excavación de urgencia que, aunque aún en estudio, plantea claramente la existencia de un taller/talleres, con firmas específicas.
} 
suponer que se trate, en nuestro caso, de una sucursal en Hispania de este alfarero del Valle del Po, pues STROBILUS únicamente se caracterizó por la producción de Firmalampen, y no lucernas derivadas de la Dr. 3 como la que aquí tenemos en consideración.

Otro elemento a considerar es la gran tradición alfarera de la antigua capital de la Bética. En el terreno lychnológico, los datos con que contamos hasta el momento nos permiten asegurar la existencia de talleres manufactureros de lucernas tardorrepublicanas a imitación de los tipos del siglo I a.C. de procedencia itálica ampliamente documentados por todo el Mediterráneo. Por otro lado contamos con la producción a la que acabamos de hacer alusión que parece centrarse en época media y bajoimperial. Notamos, por tanto, un claro hiatus en una época en la que parece que tras las masivas importaciones itálicas de época precedente (siglo । d.C., sobre todo), y frente al empuje de las primeras producciones africanas comienzan a florecer las industrias de carácter local.

\section{Tipologias encontradas en Córdoba}

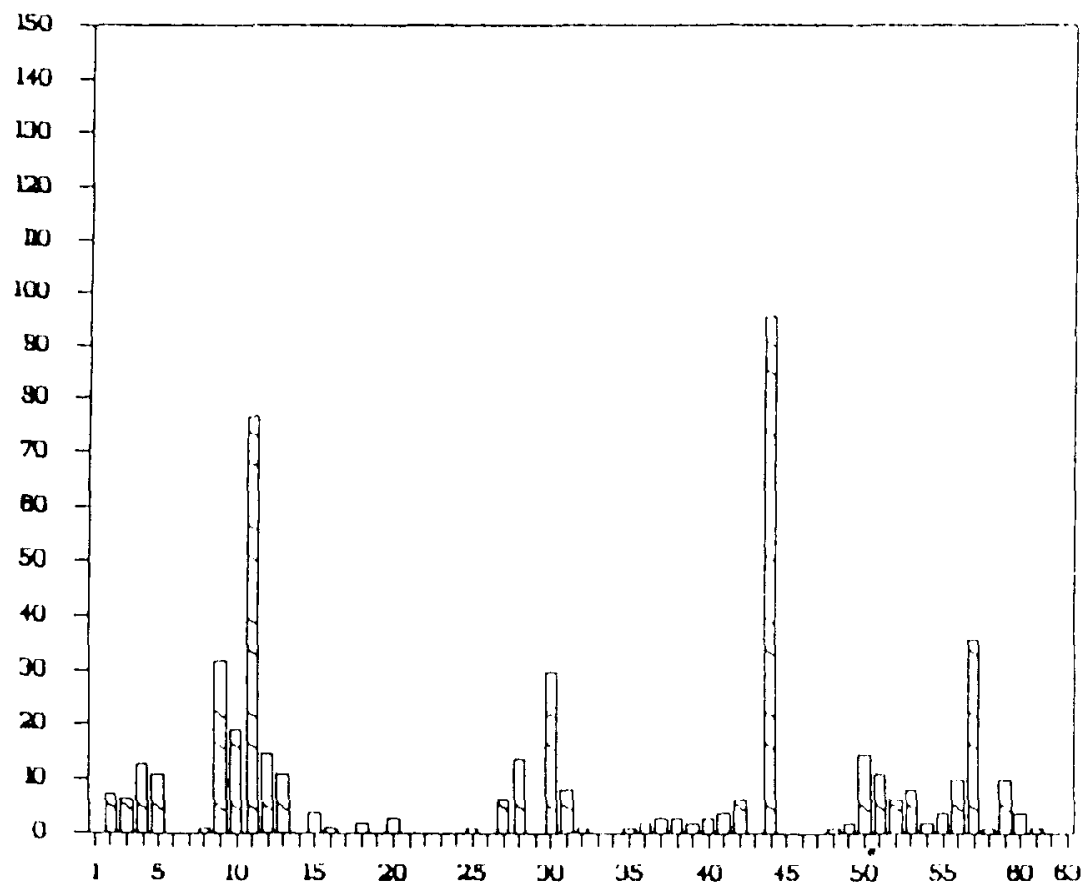

Fig. 2. Concentración de los tipos de lucernas romanas en Córdoba (según Mo. RENO1990, pág. 1759. 
Por último, nos gustaría entresacar ciertos datos de la distribución espacial de la forma en la Hispania romana. A nivel cartográfico (fig. 3) observamos una concentración de la producción al Sur de Sierra Morena, confirmando el carácter regional de su comercialización, tal y como ya había sido advertido. Esta concentración, fundamentalmente sureña, ya quedó planteada por López Rodríguez, que de los 19 yacimientos por él aportados (fig. $3, n^{\circ}{ }^{\circ} 1-19$ ), sólo seis quedaban en territorio extrabético $(1982,390)$. Junto a ellos, una pieza sin procedencia del Museo de Albacete (Sanz-Gallego 1982, 205). Otra más en Mérida (Serrano 1983, 151) y las de Singilia Barba (SERRANo 1988, 821), documentadas bajo los niveles del vertedero del taller de $\mathrm{TSH}^{11}$. A ellas debemos sumar una de Calahorra (AMARé 1987, 67, lám. I, n. ${ }^{\circ}$ 2a, b) y tres en Bílbilis (AMARÉ 1988, 40, lám. III). Beltrán hace referencia, junto a las ya mencionadas, a lucernas tipo Andújar en Cádiz, Cástulo, Cerro de Montecristo (Adra, Almería), La Bienvenida -en territorio bético- y Astorga y posiblemente Mieiras de Beloño en el Norte peninsular (1990, 270). A continuación tenemos las piezas de las galerias romanas de la Cueva de la Barrera Blanca (León) y Complutum, aportados por Amaré (1989-1990, 144). Además, adjuntamos tres en Segóbriga (Cuenca), una pieza en el Museo de Santander y otra más en Herrera de Pisuerga ${ }^{12}$. Junto a ellos, la acentuación de los porcentajes en la Bética es, como ya hemos indicado, más que notable, a raíz de los datos presentados por Moreno, cuyas novedosas aportaciones enumeramos a continuación. En Almeria, una pieza en el Campo de San Juan $(1991,736)$; en Granada, junto a las ya existentes, una nueva en Guadix (1991, 1.094-1.095); cuatro lámparas en Málaga capital, una en El Castillón y nuevos datos en los Castillones (Singilia Barba) que sumados a los ya conocidos hacen ocho en total $(1991,1247$ 1250); ningún ejemplar gaditano ${ }^{13} \mathrm{y}$ en la provincia de Huelva uno sólo en Riotinto (1991, 1111-1190); Sevilla capital ofrece ya una decena de piezas, junto a otras tantas en Osuna, tres ya en Italica y cinco nuevas en Écija, 14 en Estepa, dos en Marchena y una en Cañada Honda (1991, 909-1.069). En Córdoba se han registrado unas 80 piezas, otras 10 en Cerro Muriano, cuatro en Montilla, dos más al ya existente en Baena, tre en Fuente Tójar, dos en Nueva Carteia y Cabra y, por último, una pieza

Realmente no sabemos si en Singilia Barba se fabricaron este tipo de materiales asociados a la producción de TSH conocida y de cerámica común (SERRano 1991, pág. 16). Debemos por tanto esperar a la publicación del resto de las categorias cerámicas para poder valorar esta posibilidad.

12 Estos tres últimos datos han sido gentilmente proporcionados por A. Morillo. El ejemplar de Herrera de Pisuerga corresponde al frag. La Serna n. ${ }^{\circ} 14$, del tipo D1 de Sotomayor, hallado en un contexto flavio, pero adelantable a época neroniana (Mofillo 1992, fig. 11.4 y lám. 4).

13 Frente a Beltran (1990, pág. 270) que cita piezas en Cádiz. 
en Peñaflor, Palma del Río, Espejo, Cañete de Torres, Pedro Abad y Cerro de la Cabeza Baja y Alta (1991, 909-1069); en Jaén, y frente a las 40 aproximadamente conocidas ya en Andújar, dos más en la capital, tres en Martos y una sola en Porcuna, Úbeda, La Carolina, Santo Tomé y, finalmente, en Santa Elena (1991, 1.215-1.228). Fuera del entorno andaluz, pero aún en la Bética, tenemos nueve ejemplares en Badajoz: cinco en Zalamea, dos en la propia capital y sendos ejemplares en Azuaga y en Fuente del León (1991, 809-810). Por último, en La Bienvenida (Ciudad Real), el número de piezas asciende ya a 25 (1991, 900-906) ${ }^{14}$.

En cuanto al panorama septentrional peninsular son algunas las precisiones que podemos plantear, soslayando la dificultad ya referida de la mayor o menor intensidad de estudios en las diversas zonas.

En primer lugar, la concentración en Andalucia, sobre todo en su parte alta, nos da las pautas del carácter de esta producción: regional y con ramificaciones de mediana importancia en el territorio andaluz colindante. El origen de la distribución de la misma aparece, sin lugar a dudas, vinculado al factor oleícola, pues el reducido coste económico y la fácil adquisición de este producto han sido considerados como determinantes en el surgimiento de alfarerías de este tipo ${ }^{15}$ y en nuestro caso aún más.

Respecto a las vías de distribución, es la terrestre la que tiene prioridad. Sin duda alguna, el comercio a pequeña escala utilizaba ese camino y la aparición esporádica de piezas en la Meseta y en el Norte peninsular parecen abogar por ello. Esta dispersión norteña, y tal y como ha sido recientemente considerado, seguía la Vía de la Plata (Morillo 1992).

En el estricto caso del taller de Andújar y conscientes del alcance norteafricano (Mauritania Tingitana) de su producción de TSH (ROCA 1991b, 232-233), la no documentación de esta forma en los yacimientos tingitanos (PONSICH 1961, passim) nos induce a plantearnos la posibilidad de su comercialización de ambas categorías, TSH y lucernas, por sepa-

\footnotetext{
Debemos añadir una pieza de procedencia desconocida conservada en el Museo de Santa Cruz (Toledo), aún en trámites de publicación (ZaRZALEJos Prieto, M., "Lucernas romanas inéditas del Museo de Santa Cruz (Toledo", Lucentum, en prensa).

Son muy interesantes los planteamientos de TARRADELL, M., "La expansión del aceite y el uso de lucernas. Un elemento metodológico para la Historia agraria del Mediterráneo antiguo", Actas de las Primeras Jornadas de Metodología Aplicada a las Ciencias. Santiago de Compostela 1975, págs. 173-184. Es interesante contrastar el paralelismo, aunque en un contexto espacial y cronológico diferente, en PAVOLINI, C., "Ambiente e illuminazione. Grecia e Italia fra it vil e it ill secoli prima Cristo", Opus, I, 2, 1982, págs. 291-313.
} 
rado y de manera independiente ${ }^{16}$. Posteriores hallazgos contribuirán a aclarar este punto.

Debido al carácter ciertamente puntual de los hallazgos de la zona norte de la Península y dada la ausencia de datos que permitan pensar en la existencia de un centro productor de estas formas fuera de la Béti$\mathrm{ca}^{17}$, los consideramos como exportaciones de estos talleres béticos (de los cuales conocemos por el momento el de Andújar y el de Córdoba capital), debiendo interpretarlos como curiosidades o más bien asociadas a la distribución olearia.

A modo de conclusión, y ya argumentada la existencia en Córdoba de un taller/talleres, sólo nos queda esperar que nuevas actuaciones de urgencia en el casco urbano de la ciudad nos permitan conocer su ubicación espacial precisa mediante el hallazgo de elementos físicos, moldes, hornos o vertederos que así lo testimonien.

\section{BIBLIOGRAFIA}

Atlante I = CARANDINI, A. (1981): "Introduzione", Atlante delle forme ceramiche. I. Ceramica fina romana nel bacino Mediterraneo. EAA. Roma.

Atlante $\|=$ MEzQUIRIz, M. A. (1985): "Terra sigillata Hispanica", Atlante delle forme ceramiche. II. Ceramica fina romana bel bacino Mediterraneo. EAA. Roma.

Amaré Tafalla, M. T. (1987): Lucernas romanas de La Rioja. Logroño.

- (1988): Lucernas romanas en Aragón. Zaragoza.

- (1989-1990): “Lucernas romanas en Hispania (las lucernas romanas de cerámica en la Península Ibérica hasta el siglo $\mathrm{v}$ : introducción y elementos de trabajo)", Anas, n. ${ }^{\text {os }}$ 2-3. Mérida, págs. $135-172$.

BeltRÁn LloRis, M. (1990): Gui a de la cerámica romana. Zaragoza .

Bernal Casasola, D. (1991-92): “fig uli hispani: testimonios materiales de manufactura peninsular de lucernas en época romana”, Opus, IX-X, Siena, págs. 147-159.

Fernández Ochoa, C.; Seldas, I. y Caballero, A. (1987): "Las lucernas romanas de La Bienvenida (Ciudad Real)», Oretum, III, págs. 263-290.

López Rodriguez, J. R. (1982): "Cuatro lucernas hispanorromanas", en Homenaje a C. Fernández Chicarro. Madrid, págs. 381-389.

Marfil Ruiz, P. y Ventura Villanueva, A. (1991): Arqueología Urbana (catálogo de la exposición organizada por el Colegio Oficial de Arquitectos y el Convenio de Colaboración Cultural). Córdoba.

MOREL, P. (1990): "La produzione artigianale e il commercio transmarino", en Storia di Roma. II. Parte Seconda, L'egemonia mediterranea. Turin, Ed. Einaudi, págs. 399-412.

Moneno Jimenez, F. (1991): Lucernas romanas de la Bética, t. I. II y III. Madrid.

${ }^{165}$ En cambio, en el territorio peninsular hay casos claros como el de La Bienvenida, que evidencian la comercialización conjunta de las vajillas finas del taller de TSH jiennense con lucernas tipo Andujar (FEANÁNDEZ OCHOA 1987, pág. 269)

17 Hecho poco probable, pues el incremento del número de estudios en la zona en cuestión en los últimos años permite valorar el fenómeno con una mayor fiabilidad y apuntan en esta dirección. 
--, "Lucernas tardorrepublicanas de decoración radial», en Homenaje a A. M. Vincent (en prensa).

Morilzo Cerdan, A. (1992): Cerámica romana de Herrera de Pisuerga (Palencia): lucernas. Santiago de Chile.

PavolinI, C. (1983): "Considerazioni sulla diffusione delle lucerne in terra sigillata prodotte in Tunisia", Opus, II. 1, págs. 43-51.

PONSICH, M. (1961): "Les lampes romaines en terre cuite de la Maurétanie Tingitane", Publications du Service des Antiquités du Maroc, n." 15. Rabat.

Roca Roumens, M. (1991): "Estado actual y perspectivas de la investigación de los centros productores de Terra Sigillata Hispánica: el ejemplo de Los Villares de Andújar, Jaén", Florentia lliberritana, $n .{ }^{\circ}$ 1. Granada, págs. 389-407 (= RocA 1991a).

--, (1991): “Producción y comercialización de la sigillata producida en la Bética", en La Bética en su problemática histórica (C. González Román ed.). Granada, págs. 221-235 (- RocA 1991b).

Sanz Gamo. R. y Gallego, I. (1982): "Lucernas romanas del Museo de Albacete", Anales del Centro de la Uned n. 4 , págs. 203-242.

Serrano Ramos. E. (1983): "Dispersión de la Sigillata Hispánica fabricada en los talleres de la Bética», Boletin del MAN, 1, 2. Madrid, págs. 151-157.

--, (1988): "Singilia Barba, una ciudad de la Bética", / Congreso Int. El Estrecho de Gibraltar (Ceuta 1987). Madrid, t. I, págs. 821-831.

-, (1991): Terra Sigillata Hispánica de los alfares de Singilia Barba. Málaga.

Sotomayor Muro, M.; Roca, M.; Sotomayor, N. y Atienza, R. (1981): “Los alfares romanos de Los Villares de Andújar (Jaén, campaña 1978-1979)", NAH. n. 11. Madrid, págs. 309.316.

Ventura Villanueva, A. (1991): "Resultados del seguimiento arqueologico en el solar de calle Ángel de Saavedra, n." 10, Córdoba», AAC. Córdoba, págs. 253-290.

\section{RESUMEN}

Presentamos aquí una lámpara romana de producción hispana localizada en los fondos antiguos del Museo Nazionale Romano (Roma), correspondiente a un tipo conocido como derivado de la Dressel 30 "de Andújar», de cronología altoimperial (siglo । d.C.). Adjuntamos ciertos datos que nos permiten asegurar su fabricación no sólo en el yacimiento jienense ya documentado, sino también en la vecina capital bética, Córdoba.

\section{ABSTRACT}

We present here a roman lamp manufactured in Spain found in the old collection of the Museo Nazionale Romano (Rome) of a type known as derived from the Dressel 3 or "from Andújar». We include some details that let us assure its production not only in the settlement of Los Villares (Jaén), but also in the capital of the Betica, Córdoba. 